\title{
O LUGAR DA PRÁTICA NA FORMAÇÃO INICIAL DE PROFESSORES: O CONCEITO DE PREPARO PRÁTICO EM CONTEXTOS DE INSERÇÃO À DOCÊNCIA NO BRASIL
}

\author{
Nathália Cristina Amorim Tamaio de SOUZA ${ }^{1}$ \\ Maria Regina GUARNIERI ${ }^{2}$
}

Resumo: A partir de uma discussão que focaliza a ineficiência dos modos convencionais de inserção à docência no Brasil, este artigo objetiva apresentar um conceito relativamente inédito e suas potencialidades para repensar o momento reservado para a prática na formação inicial de professores. Trata-se do conceito de preparo prático, fundamentado nas contribuições de Marcelo, Gauthier et al. e Gimeno. A investigação empreendida, de natureza teórica, apresenta como principal indicativo a necessidade de os cursos de formação reverem suas estratégias de inserção à docência, pautando-se em um modelo de inserção orgânica que propicie ao futuro professor, por intermédio de intervenções práticas organizadas, um preparo consistente para o início da profissão docente.

Palavras-chave: Formação inicial de professores. Inserção à docência. Preparo prático.

\section{Introdução}

No se puede seguir ignorando que existe una fase claramente diferenciada en el proceso de convertirse en un buen profesor, que tiene sus propias características y necesidades, y que funciona como un eslabón entre la formación inicial del profesorado y su futuro desarrollo profesional.

Carlos Marcelo (2011, p. 34).

A formação de professores vai se configurando progressivamente como um âmbito imperativo para a apreciação da qualidade dos sistemas educativos, uma vez que nela residem elementos definidores do trabalho dos protagonistas da educação. Essa ponderação, que confere grande responsabilidade à formação docente, tem sido

\footnotetext{
${ }^{11}$ Formadora de Orientadores de Estudo no âmbito do Pacto Nacional pela Alfabetização na Idade CertaPNAIC/MEC da UNESP. Toddler Desenvolvimento Infantil. São Paulo - SP - Brasil. 04552-030 nathytamaio@fclar.unesp.br

${ }^{2}$ Líder do Grupo de Pesquisa "Trabalho docente e suas relações com o universo escolar e a sociedade", cadastrado no Diretório dos Grupos de Pesquisa do CNPq. UNESP - Universidade Estadual Paulista "Júlio de Mesquita Filho". Faculdade de Ciências e Letras - Pós-Graduação em Educação Escolar. Araraquara - SP - Brasil. 14800-901 - mreginag@ fclar.unesp.br
} 
recorrente em centenas de obras desde o início da década de 1990 e, atualmente, estimase que represente uma legítima tendência de estudos em educação.

Como já se sabe, quando um tema desperta tão forte mobilização na esfera acadêmica, ao menos dois aspectos podem ser conjecturados. O primeiro deles é altamente promissor: diz respeito à ampliação de conhecimentos sobre o campo de estudos em questão e, considerando-se a complexidade inerente à formação de professores, seja ela inicial ou permanente, é impossível negar que ainda há muito para se conhecer. O segundo aspecto, por sua vez, pressupõe a existência de falhas e desacordos que provocam os estudiosos. Tal proposição é corroborada pela expressiva parcela de estudos que revela um descompasso entre o que se espera da aprendizagem da docência e o que, de fato, se obtém.

$\mathrm{Na}$ esteira da realidade inquietante trazida pela literatura da área, pesquisas recentes que investigaram o processo de formação e a iniciação profissional de professores em diferentes países, como as produzidas por Marcelo (2011) e Zeichner (2010), alegam que a aprendizagem docente só expressará efeitos significativos se houver um espaço na formação inicial reservado para uma preparação consubstanciada na e a partir da prática, ou seja, um momento de inserção dos futuros professores à docência.

Cabe assinalar, porém, que não se trata de uma inserção descontextualizada e sem planejamento como ocorre habitualmente, mas de um processo comprometido com a evolução daqueles que se encontram no limiar da transição estudante-professor, ou, conforme sugere a epígrafe destacada nas linhas iniciais deste texto, um processo que funcione como elo entre a formação inicial de professores e seu futuro desenvolvimento profissional.

No caso do contexto brasileiro, território no qual se concentram as reflexões aqui engendradas, o que se verifica é justamente a ausência de preparo e assessoria aos licenciandos que se inserem nas escolas de Educação Básica. Mesmo que se admita a ineficiência da prática de "depositar" estagiários no interior das salas de aula, orientados a "aplicarem" o que aprenderam no meio acadêmico, esse modelo é o que ainda prevalece.

Diante desse cenário, uma indagação não pode ser evitada: “O que falta, então, para que os cursos de formação inicial de professores repensem suas estratégias de inserção à docência?”. Indagação esta eleita como fio condutor do artigo que ora se inscreve, cujo objetivo é advogar que para uma inserção à docência adequada se 
consolidar, é preciso que seja assegurado um preparo prático - conceito relativamente inédito a ser apresentado em seção oportuna - aos futuros professores.

Ao proceder assim, compete explicitar a estrutura sequencial que dará sustentação a este trabalho.

$\mathrm{O}$ artigo subdivide-se em duas seções principais. A seção inicial focaliza o tratamento dado ao desenvolvimento de atividades práticas no interior dos cursos de formação inicial de professores, destacando estudos realizados no Brasil que versam sobre o estágio curricular supervisionado, e desdobra-se em outras duas subseções que abordam, respectivamente, os problemas e as possibilidades para repensar a inserção de licenciandos nas escolas. A seção seguinte, pautando-se no referencial adotado (GAUTHIER et al., 1998; GIMENO, 2000, 1995; MARCELO, 2011, 1999, 1991), valese dos indicadores apresentados ao longo do texto para inserir o conceito de preparo prático e explorá-lo enquanto meio viável de suprir as falhas do modo atual de inserção à docência.

\section{A prática nos estágios curriculares supervisionados: o contexto brasileiro em foco}

Atender às necessidades reais apresentadas pelo cotidiano escolar é uma tarefa que se coloca à atividade docente e vai além da prática de aplicar uma teoria aprendida ou repetir métodos e procedimentos utilizados por outrem. Trata-se, pois, de saber relacionar crítica e reflexivamente o conhecimento teórico e a iniciação às atividades de natureza prática, edificados ao longo da trajetória de formação, às especificidades das realidades locais.

No entanto, estados da arte nacionais (ANDRÉ, 2002; GATTI; BARRETO, 2009) evidenciam reiteradamente que os professores não vêm recebendo apoio suficiente para enfrentar as demandas atuais da escola pública, e tampouco para assumir novas atribuições às quais são cobrados diariamente no exercício da profissão. Acreditase que essa carência de subsídios que despertam o sentimento de despreparo no futuro professor seja decorrente, entre outras causas, da maneira dicotômica com que teoria e prática são concebidas.

Ainda que se verifique uma forte preocupação com a busca pela indissociabilidade entre teoria e prática nos discursos sobre educação (PIMENTA, 2001), o que se tem observado é a crescente cisão desses dois polos do conhecimento. Isso porque a imagem mais disseminada acerca da docência, presente nas frases "Só se aprende a ser professor na prática" ou "Na prática, a teoria é outra", tem gerado uma 
supervalorização da experiência e a ligeira confusão de que a expressão "prática" constitua unicamente o exercício efetivo da profissão, desvinculando-a de qualquer atividade desempenhada ao longo do curso, como os estágios curriculares. Destarte, observa-se a intensificação de um problema que há tempos se instaura no processo de preparação profissional de professores: o distanciamento entre o que se aprende na formação inicial e o que se faz na atuação docente (GUARNIERII, 2012).

Apesar das críticas e insistências advindas do meio científico, dos avanços no que tange ao significado atribuído aos estágios curriculares no decorrer dos anos e até mesmo das tentativas de alguns cursos em reconhecer que o estágio deve permear toda a formação e ser compreendido como o momento de se sentir a dimensão do "ser professor", esse espaço ainda tem se mostrado insuficiente para que o licenciando tenha condições de assimilar a complexidade dos problemas existentes no meio escolar. Pimenta e Lima (2004) assinalam que o modo atual de realização dos estágios permanece inclinado à cultura tecnicista, ou seja, a um modelo baseado na informação, na observação, nos relatos e descrições, que coloca o licenciando sempre na condição de mero expectador.

Tais colocações antecipam os indícios, abordados a seguir, sobre a precariedade das ações práticas veiculadas pelos estágios. Lembrando que a prática em questão não se refere estritamente ao exercício profissional docente, mas a um componente préprofissional que deve assumir "o lugar de aprendizagem e de construção do pensamento prático do professor” (SILVA, 2009, p. 31).

Assim, faz-se relevante questionar: que fatores influenciam a descaracterização da função primária dos estágios curriculares, que seria munir o futuro professor de habilidades que lhe oportunizem iniciar a carreira docente com segurança? E que medidas poderiam ser tomadas em favor da potencialização da inserção à docência? Responder a essas questões implica revisitar os dados consolidados pelas pesquisas atuais que tratam do assunto.

\section{Problemas na inserção dos licenciandos no cotidiano das escolas}

A forma com que os estagiários são inseridos nas escolas define em parte como será o nível de sua aprendizagem acerca dos elementos que gravitam em torno do universo escolar e da docência propriamente dita. Portanto, deve-se observar, inicialmente, como se efetiva a relação da universidade com o grupo de escolas da rede 
de ensino que recebem seus alunos, e se a inserção dos mesmos ocorre de maneira orientada e planejada ou não.

Com relação a isso, as próprias Diretrizes para a Formação Inicial de Professores para a Educação Básica (BRASIL, 2000, p. 23), declaram que o contato entre as duas instituições formadoras é restrito e inconstante, o que evidencia a primeira falha desse momento, pois por vezes acaba ficando "a cargo do próprio estagiário escolher e entrar em contato com a escola em que fará estágio".

Outro aspecto que merece destaque diz respeito ao tipo de atuação exercido pelo estagiário. Já se sabe pelas pesquisas (GATTI, 2000; GATTI; BARRETTO, 2009; MARCELO, 1999; PIMENTA; LIMA, 2004) que os licenciandos que têm a oportunidade de vivenciar de forma orgânica as múltiplas facetas pedagógicas costumam sofrer menos impactos ao iniciarem a carreira profissionalmente. Isso acontece porque podem ser capazes de estabelecer atitudes e estratégias adequadas a determinado contexto por possuírem conhecimentos práticos consideravelmente superiores àqueles que não tiveram um contato estreito e ativo com o manejo de situações reais em sala de aula durante a realização do estágio.

Se o aprendiz-professor tem a possibilidade de elaborar atividades em parceria com o professor responsável pela sala de aula e aplicá-las conjuntamente, está aprendendo tanto a conciliar o conhecimento específico do conteúdo aos meios mais adaptados de transmiti-lo à turma, quanto a desenvolver, implicitamente, a socialização profissional e estratégias de autonomia para sua atuação futura.

Significativa parcela da literatura brasileira sobre formação de professores e inserção à docência permite afirmar que os estagiários que, por sua vez, simplesmente observam as práticas dos professores sem poderem intervir tendem a trilhar um dos caminhos opostos entre si: repetir acriticamente os mesmos procedimentos utilizados pelo professor observado, desconsiderando as particularidades de sua turma; ou condenar a postura do professor, alegando que durante o estágio aprendeu somente o que não se deve fazer em sala de aula.

Verifica-se, pois, que esse empecilho tem sido recursivo, uma vez que, segundo Guarnieri (2012, p. 5) “[...] os professores resistem em aceitar que os estagiários possam dar aulas para suas turmas ou que desenvolvam atividades trazidas por eles a partir do que estão aprendendo no curso e do que vivenciam durante esse contato com as professoras." 
A autora destaca que são cada vez mais raros os momentos de intervenção e interação do estagiário com as situações de ensino, com ressalva às solicitações, por parte dos professores, para que ele acompanhe um ou outro aluno que apresenta maiores dificuldades. A dinâmica desse tipo de atividade habitualmente segue o padrão em que o estagiário e o aluno (ou um pequeno grupo de alunos) acomodam-se em carteiras no fundo da sala de aula, isolados do restante da turma, enquanto o professor prossegue com os afazeres cotidianos conduzindo a parcela majoritária de alunos, cujos ritmos de aprendizagem são mais ou menos homogêneos. Outro tipo de solicitação muito comum é que o estagiário realize atividades secundárias de cunho não pedagógico (empilhamento e distribuição de livros, recortes e colagens, chamada de alunos presentes, impressão ou xérox de material didático).

Desse modo, nota-se que a aprendizagem da docência ainda está distante de ocorrer, tanto pela maneira inadequada e sem orientação com que os alunos são inseridos nas escolas quanto pela forma como os professores percebem os estagiários.

Reforçando essas evidências, Santana e Inforsato (2011, p. 4) destacam os problemas presentes na dimensão curricular dos cursos de licenciatura, tais como:

[...] a desconsideração dos conhecimentos e experiências dos professores em formação, o tratamento inadequado dos conteúdos e a desarticulação entre os acontecimentos pedagógicos e os de ensino, falta de oportunidades para o desenvolvimento cultural, tratamento restrito da atuação profissional, concepção restrita da prática, inadequação do tratamento da pesquisa, ausência de conteúdos relativos às tecnologias da informação e das comunicações, desconsideração das especificidades próprias dos níveis e/ ou modalidades de ensino em que são atendidos os alunos da educação básica e a desconsideração das especificidades próprias das áreas do conhecimento que compõem o quadro curricular da Educação Básica.

Um último fator elencado para justificar a ineficiência da inserção dos estágios nas escolas se traduz pelo que Guarnieri (2012) denomina como "mensagens negativas". Tais mensagens, transmitidas pelos professores das escolas de Educação Básica aos estagiários se caracterizam como "desabafos", e geralmente referem-se ao stress diário decorrente da extensa jornada de trabalho, da falta de cooperação e reconhecimento da equipe gestora e do desprestígio e desvalorização social da profissão.

Das mensagens propaladas, a que mais se intensifica ao longo do tempo diz respeito à desvalorização do ofício docente. Ainda que as mensagens denotem o 
descontentamento dos professores em face das condições de trabalho - que de fato são problemáticas - elas podem:

[...] desestimular os futuros professores a optarem pela profissão conduzindo-os a se engajarem em atividades de pesquisas, sempre mais valorizadas na universidade, ou ainda, para aqueles que pretendem ser professores alimentarem percepções e crenças de que basta gostar dos alunos, ter paciência, convicção e vocação que já possuem o suficiente para ser professor. (GUARNIERI, 2012, p. 4).

Por fim, o que se infere com base nos apontamentos dessa subseção é que o modelo em que tradicionalmente a inserção à docência é desenvolvida nos cursos de formação de professores não tem possibilitado a análise crítica da prática docente em sala de aula e a construção de uma atitude docente que ultrapasse a cultura escolar, ainda impregnada dos resquícios de uma perspectiva tecnicista. Isso permite dizer que os dilemas que permeiam a atuação docente no Brasil dificilmente serão superados se não forem tomadas medidas de revisão da formação inicial, por ser justamente nesse período que se enraízam as primeiras e decisivas falhas a serem refletidas no processo educativo.

\section{Possibilidades para o fortalecimento da inserção à docência}

Ao analisar o problema da ineficiência da inserção de futuros professores à docência pelos estágios e o desafio constante de sua superação para além dos discursos, Pimenta (2001) ressalta que embora os cursos de licenciatura estruturem-se de forma fragmentada, valorizando as disciplinas teóricas e contendo uma série de fragilidades, ele é (ou pelo menos deveria ser) uma atividade viabilizadora e instrumentalizadora da práxis do futuro professor; uma peça fundamental no processo de tornar-se professor e no desenvolvimento da atividade docente. Essa afirmação, ao mesmo tempo em que sinaliza a existência de entraves e contradições que perpassam a formação, exprime certa esperança na possibilidade de ressignificá-la considerando a força que ela própria detém.

Para tanto, o que se espera do curso de formação para a docência é o desenvolvimento de ações que propiciem ao licenciando o contato e a familiarização com o ambiente escolar, bem como o provimento de estratégias e técnicas que venham a facilitar sua inserção profissional e amenizar as tensões que, conforme alertam estudiosos como Fontana (2000) e Freitas (2002), afligem o iniciante. 
Santana e Inforsato (2011) defendem que uma maneira propícia para o desenvolvimento de práticas mais contextualizadas e eficientes na formação inicial seria a inserção do licenciando à docência desde o início do curso, pois isso facilitaria a diluição das exaustivas horas de estágio, evitando a sobrecarga nos últimos anos letivos e, consequentemente, potencializando o rendimento dos alunos. Além disso, seria possível também reduzir a sensação de estranhamento do licenciando. Esse sentimento costuma ser comum, pois após ter vivenciado durante toda a trajetória escolar e acadêmica o papel de aluno, deparar-se apenas nos anos finais do curso de graduação com o outro lado da moeda, quer dizer, o papel do professor, pode causar receios e a sensação de despreparo.

É pertinente resgatar as ponderações compartilhadas por Gatti (2013) e Libâneo (2013) em uma obra conjunta recente, na qual afirmam que para que haja mudanças significativas e promissoras na formação de futuros professores, deve-se compreender a prática pedagógica como núcleo do processo de formação.

Em outras palavras, os autores advogam que os cursos de licenciatura devem conceber a prática como elemento norteador de todas as ações formativas, articulando-a de forma mais clara e contundente aos conteúdos das disciplinas, principalmente as de Didática e de Conteúdos e Metodologias. Não faz sentido num curso de Pedagogia não existirem disciplinas que abordem os conteúdos específicos que o futuro professor trabalhará em sala de aula, revela Libâneo (2013). Assim como não faz sentido não haver um espaço de orientação para a prática em que os conhecimentos acadêmico e profissional possam, efetivamente, se entrelaçar, infere Gatti (2013) ao se remeter à ideia de criação de espaços híbridos, isto é, de espaços nos programas de formação inicial de professores que reúnem professores da Educação Básica e do Ensino Superior, e conhecimento prático profissional e acadêmico em novas formas para aperfeiçoar a aprendizagem dos futuros professores.

Embora a premissa defendida pelos autores vá ao encontro das diretrizes dispostas pela Resolução CNE nº. 1/2002 (BRASIL, 2002), as quais regulamentam que a prática pedagógica deve atravessar todo o momento da formação, sabe-se pelas pesquisas da área, pela análise das propostas curriculares dos cursos de licenciatura e até mesmo pelo estudo das ementas de disciplinas (GATTI; BARRETTO, 2009), que a rigor ela não se efetiva. Nessa direção, as autoras supracitadas enfatizam ainda que os programas de ensino das diferentes disciplinas vêm sendo cada vez mais trabalhados de forma independente da prática, caracterizando-se por uma visão burocrática. 
Diante disso, salienta-se que os cursos precisam com urgência se reorganizar de modo a superar esse modelo e, para tanto, é imprescindível que as instituições formadoras de professores percebam que além do conhecimento de disciplina o futuro docente precisa ter preparo para compreender os desafios inerentes ao processo ensinoaprendizagem.

Preparar é, portanto, a palavra de ordem. Os licenciandos precisam se sentir prontos para encarar a profissão que exercerão ao concluírem a graduação, e isso só é possível a partir de um preparo prático. Mas, o que vem a sê-lo?

O tema pode parecer autoexplicativo se o sentido epistemológico de preparo prático for considerado análogo ao de formação prática. Contudo, não é. Formação prática causa a impressão de segregação de uma formação que é teórica daquela que é essencialmente prática, enquanto o preparo prático se constitui numa relação de unidade entre teoria e prática. Prioriza o espaço em que se efetivará o trabalho do futuro professor, mas não descarta em hipótese alguma os saberes oriundos do conhecimento científico.

Embora seu sentido esteja imerso em ações formativas bem sucedidas, o conceito de preparo prático - a ser explorado na próxima seção deste artigo - não havia ganhado precisão até o momento da execução desta investigação. Desse modo, conjecturou-se modestamente delineá-lo. Evidentemente, tal delineamento fundamentou-se em reflexões teóricas e para o significado que se buscou obter, autores como Carlos Marcelo, Clermont Gauthier e José Gimeno mostraram-se férteis.

\section{O preparo prático para a docência}

Este artigo buscou mostrar até aqui um breve panorama do modelo atual de inserção à docência, ressaltando o lugar da prática nesse processo. Tendo em vista a evidente ineficiência da operacionalização da prática na formação inicial de professores, justificada pela falta de assessoria e orientação adequadas aos aprendizes da docência, vislumbrou-se apresentar uma alternativa possível para o fortalecimento dessa etapa tão importante do processo formativo a partir do que pode ser compreendido como um preparo prático para a docência.

No entanto, antes de se verificar como esse preparo se manifesta em ações formativas, é necessário compreender sua definição, suas características e pressupostos. Para isso, faz-se importante precisar o conceito-chave que o embasa, que é o conceito de prática. 
A literatura de pesquisa que focaliza a prática para a docência é significativa no campo da formação de professores, mas as compreensões acerca de seus desdobramentos são variadas e nem sempre suficientemente aprofundadas. Nesse sentido, optou-se pelo apoio teórico de Gimeno por considerar-se que suas ideias são as mais fecundas para a fundamentação da noção de preparo prático, cultivada nesta investigação.

As obras de Gimeno expressam uma infinidade de contribuições à educação e isso não se deve somente à capacidade que o autor detém para interpretar conceitualmente as mais diversas realidades que perpassam a formação e o trabalho do professor, mas também ao fato de transcenderem as explicações rasas que tanto se vê em relação aos fenômenos ocorridos no âmbito educacional. Por essa razão, os conteúdos de seus manuscritos são bastante densos e a cada nova publicação nota-se a ampliação e aprimoramento de conceitos já cunhados.

O conceito de prática, que respalda teoricamente a presente pesquisa, é trabalhado em capítulos de diferentes obras do autor (GIMENO, 1995, 2000). Na verdade, por se tratar de um conceito complexo, Gimeno não discute a prática no singular, ele tende a se referir quase sempre a práticas e suas distintas, porém articuladas, facetas.

Gimeno (1995) revela que o contexto propriamente pedagógico formado pelas práticas cotidianas de classe constitui o que vulgarmente chamamos de "prática". Não obstante, de acordo com ele, não é adequado conferir uma visão tão abreviada a uma questão tão ampla. É preciso alargar o conceito de prática, pois ela é “[...] algo fluído, fugaz, difícil de apreender em coordenadas simples e, além disso, complexa enquanto nela se expressam múltiplos determinantes, ideias, valores e usos pedagógicos [...]" (GIMENO, 2000, p. 202). Ao explicitar a existência de práticas que podem ser de caráter antropológico; pedagógico institucionalizado; e não estritamente pedagógico, o autor deixa clara essa concepção.

Admite-se que o estudo da dimensão total dos conceitos de práticas seja de grande valia, visto que elas geram influências e implicações nas questões inerentes à educação como um todo, não se restringindo às ações executadas pelo professor e tampouco ao espaço da sala de aula. Porém, o que, de fato, fornece subsídios relevantes para pensar o preparo prático via ações instauradas entre instituições - a universidade e a escola -, é o entendimento da dinâmica das práticas pedagógicas institucionalizadas, cujas facetas são estabelecidas pelo autor do seguinte modo: 
Práticas institucionais - Trata-se de práticas relacionadas com o funcionamento do sistema escolar e configuradas pela sua estrutura. A divisão entre uma via acadêmica e uma via profissional é um bom exemplo de uma prática institucional de segregação escolar e social. $[\ldots]$

Práticas organizativas - Trata-se de práticas relacionadas com o funcionamento da escola e configuradas pela sua organização: a forma de trabalho conjunto dos professores, a divisão do tempo e do espaço escolar, a articulação dos saberes e das disciplinas, os critérios de organização das turmas, etc. Estas práticas são determinadas por uma estrutura de funcionamento que abrange os professores a título individual e coletivo, influenciando de forma decisiva as actividades pedagógicas.

Práticas didácticas - Trata-se da acepção mais imediata da prática, a qual, no entanto, não pode apreender-se sem uma referência às outras práticas, que lhe servem de enquadramento e de suporte. As práticas didácticas são da responsabilidade imediata dos professores, constituindo o conteúdo de sua profissionalidade num sentido técnico e restrito. O conceito mais imediato de prática remete-nos para as atividades docentes realizadas num contexto de comunicação interpessoal. (GIMENO, 1995, p. 73).

Em decorrência do recorte focal proposto para este estudo a definição buscada é novamente filtrada, privilegiando a faceta das práticas didáticas. Tal filtro se faz pertinente uma vez que as práticas didáticas inevitavelmente se remetem às demais. Com base nas reflexões de Gimeno, depreende-se que a articulação entre as facetas das práticas ocorre numa relação de interdependência, pois o sistema escolar só tem sentido e só funciona se tiver como base as organizações internas das escolas, o que implica conhecer as disposições gerais do trabalho da equipe docente. Do mesmo modo, a organização individual e coletiva dos professores num sentido funcional só se dá na medida em que são consideradas as atividades realizadas em situações de sala de aula. Trata-se de uma relação que parte do macro para o micro, mas que, inversamente, se aplica também.

Além desse fator, a opção pelo estudo das práticas didáticas se dá em razão de as ações mais recorrentes desenvolvidas em prol da aprendizagem da prática em cursos de formação serem instrumentalizadas sob a forma de atividades docentes. Atividades essas que constituem o conteúdo da profissionalidade docente num sentido técnico (GIMENO, 1995) e que são caracterizadas como ações educativas, cujo objetivo é despertar um processo no aluno que origine efeitos convergentes com determinada finalidade pedagógica (GIMENO, 2000). 
Um conjunto de atividades docentes realizadas pelo professor em sala de aula congrega o que o autor chama de tarefa. De acordo com ele, as tarefas podem ser analisadas em função de quatro componentes básicos: o produto, os recursos, as operações e os significados. Quer dizer, “[...] uma tarefa provoca a realização de um processo ou processos dirigidos, utilizando determinados recursos e produzindo certos resultados [...]" (GIMENO, 2000, p. 210).

Em geral, as tarefas estão relacionadas aos conteúdos dos livros ou apostilas didáticos, exercícios de leituras pelos alunos e pelo professor, exercícios no quadro, comentários e discussões. São consideradas atividades todas as ações que determinam uma tarefa, como a preparação, a aplicação e a correção de um exercício, por exemplo.

Para Gimeno (2000), nesse processo de elaboração de atividades e tarefas que constituem práticas didáticas, o professor se ajusta como aquele que interfere diretamente na construção do conhecimento pelo aluno; aquele que problematiza, que mobiliza situações de ensino e aprendizagem, e que modifica a si mesmo constantemente, posto que as ações realizadas em sala de aula refletem efeitos permanentes em suas atitudes. Nas palavras do autor:

O professor é responsável pela modelação da prática, mas esta é intersecção de diferentes contextos. O docente não define a prática, mas sim o papel que aí ocupa; é através de sua actuação que se fundem e concretizam as múltiplas determinações provenientes dos contextos em que participa. (GIMENO, 1995, p. 74).

O autor prossegue proferindo que as práticas didáticas do professor em sala de aula se configuram pelos usos metodológicos, pelas avaliações dos processos de aprendizagem dos alunos, pela partilha de competências, pelo adequado uso e seleção do conteúdo, pela demarcação de normas e pelos valores sociais. Cabe dizer que esses componentes assumem papel central na caracterização do trabalho docente e que, portanto, seria indispensável que fossem incorporados desde a formação inicial. O professor é um profissional que vive em contínuo desenvolvimento e pode-se afirmar seguramente que tal desenvolvimento se inicia nos cursos de graduação. Contudo, é evidente que para isso devem ser oportunizadas experiências práticas ao futuro docente.

Gimeno (1995) sublinha que um professor que possui múltiplas experiências e significativas vivências em sua trajetória inicial, tende a consolidar práticas mais sólidas e mais contextualizadas. As experiências acumuladas sobre o processo de ensino e 
aprendizagem e de socialização compõem a ação prática e permitem o preparo para o enfrentamento da docência mais efetivamente.

Ao reconhecer a importância do acúmulo de experiências sobre o processo que envolve a socialização dos professores, os textos de Gimeno vão ao encontro dos pressupostos teóricos de Marcelo (2011, 1999, 1991), também recorridos para subsidiar teoricamente esta investigação. $\mathrm{O}$ autor explora o conceito de socialização profissional docente em muitas de suas obras e a compreende como sendo um processo mediador através do qual um indivíduo adquire o conhecimento e as destrezas sociais necessários para assumir determinado papel na organização escolar.

No âmago desse dinamismo encontram-se os professores, sejam eles iniciantes ou experientes. $\mathrm{O}$ processo de socialização se reflete em todas as etapas da docência, desde o ingresso dos professores na profissão até o encerramento da carreira, mas segundo Marcelo (1991) é durante o período de iniciação profissional que ele se intensifica, pois nesse momento o professor estabelece seu primeiro contato e suas primeiras relações com o universo escolar, criando uma atmosfera que pode ser determinante para suas ações futuras.

De acordo com Marcelo (1991), os professores iniciantes enfrentam inevitavelmente algumas dificuldades, porém quando eles estão munidos de subsídios práticos para edificar a travessia entre a condição de estudante e a condição de professor, o clima de início de carreira torna-se menos invasivo. Portanto, ainda em suas palavras, é um equívoco transferir as experiências práticas exclusivamente para o exercício profissional descartando sua viabilidade durante a formação inicial. Esse ponto de vista transparece que:

La experiencia, en el campo de la enseñanza en general, y de la formación del profesorado en particular representa una de las mayores demandas tanto de los profesores que se están formando, como de profesores en ejercicio. (MARCELO, 1991, p. 21).

Na obra em referência são apresentadas pelo autor algumas reflexões originadas de um diálogo que ele trava com a literatura da área. Em meio a elas, Marcelo indaga: “¿Qué aprenden los profesores de la experiencia?” (MARCELO, 1991, p. 23). A resposta a essa questão se faz valiosa para a presente pesquisa, pois, ao se identificar o que os professores aprendem da experiência, algumas pistas que conduzem à compreensão do preparo prático podem ser fornecidas. 
Num primeiro momento vale ressaltar que não são quaisquer experiências que agregam contribuições à aprendizagem da docência e, por assim dizer, ao preparo prático. Em um documento pulicado recentemente, Marcelo (2011) comenta os principais desafios que assolam o professor iniciante, destacando a ineficiência dos cursos de formação e a precariedade das experiências práticas por eles propiciadas. Nessa direção, o autor menciona que devem existir condições favoráveis para o desenvolvimento de experiências bem sucedidas nas salas de aula, como, por exemplo, a prática de mentoria.

Marcelo (2011) utiliza o termo mentoria para designar os docentes das unidades escolares responsáveis pelo acolhimento e acompanhamento de futuros professores ou professores iniciantes. Segundo o autor um professor mentor tem como tarefa:

[...] asesorar didáctica y personalmente al profesor principiante. El mentor desempeña un papel de gran importancia en el programa de inserción, pues es la persona que ayuda y da orientaciones, tanto en el currículo como en la gestión de clase, al profesor principiante. Esta ayuda se puede dar directa o indirectamente. Los mentores pueden proporcionar información, orientar, observar clases y dar retroacción sobre lo que ven y oyen; se pueden implicar en grupos de discusión, proporcionan relaciones con otros profesores, las instituciones de formación y la universidad, y, en algunas ocasiones, llevan a cabo la evaluación de profesores principiantes. (MARCELO, 2011, p. 19-20).

$\mathrm{O}$ autor enfatiza que os licenciandos que são acompanhados por um professor mentor têm maior possibilidade de êxito no desenvolvimento de ações práticas e da aprendizagem da docência do que aqueles que não contam com esse apoio.

É certo que, conforme enfatiza Marcelo (2011), independentemente da qualidade da formação inicial, há coisas que só se aprende na prática profissional, porém o autor garante que se bem direcionada e orientada, e se realizada em ambientes propícios à socialização com o apoio contínuo de mentores, a inserção à docência pode contribuir significativamente para a aprendizagem do trabalho docente futuro.

Marcelo (1991) também fala em condições que devem ser tomadas como parâmetro para a realização das ações práticas. São elas: conhecimento do conteúdo; conhecimento pedagógico geral (princípios e estratégias de organização de classe); conhecimento do currículo, dos métodos de ensino e de materiais; conhecimento do perfil dos alunos; conhecimento do contexto educativo; e conhecimento dos fins, propósitos e valores educativos. 
Diante dessas considerações, reforça-se que as atividades práticas desenvolvidas em contexto de experiência pré-profissional precisam ser subsidiadas por orientações para o manejo de situações reais de sala de aula e são nesses termos que se fazem imprescindíveis as conceituações de Gauthier et al. (1998), tomadas como referência para esta pesquisa. Esses autores analisam os dois momentos decisivos na organização didática do processo de ensino-aprendizagem: a gestão de classe e a gestão da matéria.

Com relação à gestão de classe, compreende-se que ela consista “[...] num conjunto de regras e de disposições necessárias para criar e manter um ambiente ordenado favorável tanto ao ensino quanto à aprendizagem [...]" (GAUTHIER et al., 1998). Saber administrar a ordem em uma classe é um desafio que se coloca ao professor, principalmente se for ajuizado o crescente problema da indisciplina dos alunos. Essa é uma realidade que exige do docente habilidade para planejar e estabelecer um conjunto de regras capazes de evitar a total desordem, mas também a ordem absoluta, pois, “[...] numa classe onde reina a ordem, é possível que certos alunos não se dediquem plenamente à atividade programada, sem, todavia, perturbar o programa de criação, criando uma situação concorrente.” (GAUTHIER et al., 1998, p.240).

Primando pelo equilíbrio da ordem em sala de aula, os autores desenvolvem análises a partir de alguns pressupostos da psicologia e da sociologia. Ressaltam que medidas baseadas em punições não são estratégias educativas adequadas, enquanto recompensas e reforços positivos têm efeitos relativos. Nota-se que as orientações de gestão de classe podem ser verificadas nos programas dos cursos de licenciatura que, em grande medida, oferecem disciplinas voltadas à psicologia, à sociologia e também à filosofia. O que não se nota, porém, é a oportunidade de os licenciandos confrontarem os estudos teóricos com a realidade escolar. Não lhes são dadas condições favoráveis para a aprendizagem do planejamento da gestão de classe, e esta é um requisito importante para a efetivação de ações de preparo prático.

No que se refere ao conceito de gestão da matéria, os autores a caracterizam como "o conjunto das operações de que o mestre lança mão para levarem os alunos a prenderem o conteúdo" (GAUTHIER et al., 1998, p. 197). Grosso modo, trata-se do planejamento dos objetivos e dos conteúdos de ensino, os quais demandam para sua realização:

- A organização do trabalho docente no que tange à determinação dos objetivos e meios de aprendizagem, pois cabe ao professor eleger as melhores maneiras de 
facilitar a aprendizagem de seus alunos e, assim, atingir os fins por ele mesmo propostos;

- A transformação dos conteúdos em consonância com os objetivos, visto que o produto final obtido através da aprendizagem dos alunos deve corresponder ao que se planejou e almejou no momento anterior à atividade realizada;

- A identificação das necessidades dos alunos para que seja possível iniciar um planejamento de atividades pertinente e provido de sentido;

- A organização do ambiente educativo, isto é, do tempo de aula previsto para o desenvolvimento de cada atividade e dos materiais e recursos utilizados durante sua execução;

- A seleção de estratégias de ensino e atividades de aprendizagem apropriadas. Os meios utilizados para ensinar devem ser convergentes aos tipos de atividades propostas, lembrando que é função do professor dominar mais de uma estratégia para cada tipo de atividade, afinal nem todos os alunos aprendem os conteúdos seguindo um raciocínio padrão;

- A sequência das atividades de determinado conteúdo, tendo em vista todas as tarefas elencadas acima;

- A especificação dos procedimentos de avaliação.

Como é possível perceber, as formulações advindas dos três autores referenciados para sustentar a noção de preparo prático se aproximam e se complementam. Os conceitos por eles propostos, principalmente os de prática(s), atividade docente, socialização profissional docente, e gestão de classe e da matéria, constituem um conjunto de elementos que o professor necessita possuir/conhecer para exercer a função de ensinar. Tendo isso muito claro, ressalta-se a importância de um preparo prático que conduza os futuros professores a esse fim.

Assim, com base na fundamentação teórica apresentada, considera-se que o preparo prático seja um processo de contínuo desenvolvimento na formação de professores. Tal processo visa à aproximação do futuro professor com o conjunto de atividades e tarefas que ele realizará ao longo do trabalho docente. É cumprido prioritariamente in loco (no interior das escolas de Educação Básica), mas também opera significativamente na universidade, por ser esse o espaço de orientação e discussão sobre a prática. Caracteriza-se pelo incentivo a vivências para além da observação de eventos cotidianos de sala de aula, ou seja, propõe atuações baseadas em 
intervenção e participação ativa dos licenciandos, consolidadas mediante provimento de condições favoráveis à constituição de práticas didáticas que se configurem por usos metodológicos e partilha de competências. E apresenta-se como incentivador da promoção de parcerias conjuntas e, por conseguinte, da socialização pré-profissional que se dá sob supervisão, assessoria e apoio de um professor (mentor) pertencente à escola em que as práticas se concretizam.

Os objetivos do preparo prático são intencionalmente projetados para despertar nos licenciandos a capacidade de, através de oportunidades de gestão de classe e da matéria, planejar, executar e avaliar atividades docentes em sala de aula convergentes à finalidade pedagógica que deve ser intrínseca ao trabalho do professor: a aprendizagem dos alunos.

Logo, como resultado de suas ações, espera-se a potencialização dos conhecimentos práticos incorporados pelos licenciandos e a minimização dos impactos que os iniciantes sofrem ao ingressarem na profissão.

\section{Considerações finais}

Neste texto almejou-se apresentar uma discussão acerca dos problemas que assolam a formação de professores no Brasil, mais especificamente o momento de inserção à docência, e também apontar alguns caminhos possíveis para que tais problemas sejam superados.

A lógica de argumentação teórica desenvolvida aqui sugere que é necessário que os cursos de formação de professores sejam repensados em sua essência, a partir da potencialização dos conhecimentos práticos. Os futuros professores precisam conhecer mais profundamente o ambiente em que atuarão após concluírem a licenciatura e, para isso, não basta que sejam oportunizadas apenas vivências de observação e aplicações de teorias.

O “chão da escola" é por si só um território de aprendizagens e não um espaço meramente designado para ensaios. A rotina, o trabalho conjunto e a execução dos conteúdos curriculares, são processos que se aprende participando como sujeito ativo, ou seja, não há prescrições teóricas capazes de substituir a riqueza de uma intervenção prática planejada.

Nessa direção, o conceito de preparo prático impresso, mais do que representar um conjunto de ideias baseadas em um referencial pertinente à discussão explicitada, propõe uma orientação. E, apesar de o estudo não pretender de forma alguma esgotar o 
assunto, infere-se que o desenvolvimento de práticas pedagógicas assessoradas deve ser considerado ponto de partida e de chegada para uma formação sólida.

THE PLACE OS PRACTICE IN INITIAL TEACHER EDUCATION: LOCATING THE CONCEPT OF PRACTICAL PREPARATION IN CONTEXTS OF INSERTION TO TEACHING IN BRAZIL

Abstract: From a discussion that focuses the inefficiency of conventional modes of insertion to teaching in Brazil, this article aims to presents a relatively new concept and its potential to rethink the time allowed to practice in initial teacher education. This is the concept of practical preparation, based on the contributions of Marcelo, Gauthier et al. and Gimeno. The research carried out, of theoretical nature, has as central indicator the need of the training courses to review their insertion to teaching strategies, guided into an insertion organic template that provides the future teacher, through practical interventions organized, a consistent preparation for the beginning of the teaching profession.

Key words: Initial teacher education. Insertion to teaching. Practical preparation.

\section{REFERÊNCIAS}

ANDRÉ, M. E. D. A. (Org.). Formação de professores no Brasil (1990-1998). Brasília: MEC, 2002.

BRASIL. Resolução CNE/CP n. 1/2002: diretrizes curriculares nacionais para a formação de professores da educação básica. Diário Oficial [da] União, Brasília, 04 mar. 2002. Seção 1, p. 8.

BRASIL. Diretrizes para a formação inicial de professores da educação básica em cursos de nível superior. Brasília: MEC, 2000.

FONTANA, R. C. Trabalho e subjetividade: nos rituais da iniciação, a constituição do ser professora. Cadernos CEDES, Campinas, ano 20, n. 50, p. 103-119, 2000.

FREITAS, M. N. C. Organização escolar e socialização profissional de professores iniciantes. Cadernos de Pesquisa, São Paulo, n. 115, p. 155-172, 2002.

GATTI, B. A. A prática pedagógica como núcleo do processo de formação de professores. In: GATTI, B. A. et al. (Org.). Por uma política nacional de formação de professores. São Paulo: Ed. da UNESP, 2013. p. 95-106.

GATti, B. A.; BARRETTO, E. S. S. Professores do Brasil: impasses e desafios. Brasília: UNESCO, 2009. 
GATTI, B. A.; BARRETTO, E. S. S. Formação de professores e carreira: problemas e movimento de renovação. Campinas: Autores Associados, 2000.

GAUTHIER, C. et al. Por uma teoria da Pedagogia. Ijuí: Ed. da Unijuí, 1998.

GIMENO, J. O currículo: uma reflexão sobre a prática. Porto Alegre: ArtMed, 2000.

GIMENO, J. Consciência e acção sobre a prática como libertação profissional dos professores. In: NÓVOA, A. (Org.). Profissão professor. Porto: Porto Editora, 1995. p.63-93.

GUARNIERI, M. R. Permanências e novos desafios da formação inicial: contribuições da didática e práticas de ensino na preparação de professores. In: LEITE, Y. U. F. et al. (Org.). Políticas de formação inicial e continuada de professores. Araraquara: Junqueira \& Marin, 2012. Livro 2. p.107-120.

LIBÂNEO, J. C. Licenciatura em Pedagogia: a ausência dos conteúdos específicos do ensino fundamental. In: GATTI, B. A. et al. (Org.). Por uma política nacional de formação de professores. São Paulo: Ed. da Unesp, 2013. p. 73-94.

MARCELO, C. Políticas de inserción en la docencia: de eslabón perdido a puente para el desarollo profesional docente. Santiago: Preal, 2011.

MARCELO, C. Formação de professores para uma mudança educativa. Porto: Porto Editora, 1999.

MARCELO, C. Aprender a enseñar: un estúdio sobre el proceso de socialización de profesores principiantes. Madrid: CIDE, 1991.

PIMENTA, S. G.; LIMA, M. S. L. L. Estágio e docência. São Paulo: Cortez, 2004.

SANTANA, A. C. M. S; INFORSATO, E. C. O estágio supervisionado na formação docente. CAMINE: Caminhos da Educação, Franca, v. 3, n. 1, 2011.

SILVA, M. Complexidade da Formação docente: saberes teóricos e saberes práticos. São Paulo: Cultura Acadêmica: Ed. da UNESP, 2009.

ZEICHNER, K. M. Repensando as conexões entre a formação na universidade e as experiências de campo na formação de professores em faculdades e universidades. Revista Educação, Santa Maria, v. 35 n. 3, p. 479-504, 2010. 